\title{
DESCRIÇÃO DO PERFIL EPIDEMIOLÓGICO DA POPULAÇÃO INFECTADA COM TUBERCULOSE NO ESTADO DO PARANÁ
}

\author{
DESCRIPTION OF THE EPIDEMIOLOGICAL PROFILE OF THE \\ POPULATION INFECTED WITH TUBERCULOSIS IN THE PARANA STATE
}

Tais Lorrane Mendes Silva*, Gustavo Cardoso Gomes' Júlia Maria Orsini Zava, Karla Mara Oldoni, Natália Nichele Barbosa, Sandra Sayuri Nakamura de Vasconcelos.

UNINGÁ - Centro Universitário Ingá, Maringá, PR, Brasil. *taisIms@hotmail.com

\section{RESUMO}

A tuberculose é uma doença infectocontagiosa, causada pelas micobactérias do complexo Mycobacterium tuberculosis, conhecidas como bacilos de Koch. Inicialmente a doença pode apresentar um período de latência seguido por um período sintomático, existindo duas formas da apresentação, a pulmonar e extrapulmonar, sendo possível a coexistência de ambas. Os principais sinais e sintomas que o paciente pode apresentar, caso desenvolva uma tuberculose pulmonar, são: tosse, febre, cansaço, dor no peito entre tantos outros sintomas, bem como, pode ser assintomático. A transmissibilidade dessa forma ocorre por gotículas eliminadas pela respiração, espirro ou tosse do portador, que se comporta como um reservatório. A patogênese da extrapulmonar inclui inoculação do patógeno com lesão local no órgão, disseminação, linfática, por contiguidade ou hematogênica. O presente estudo objetiva levantar o número de casos confirmados, bem como, traçar o perfil epidemiológico dos pacientes com tuberculose no Estado do Paraná e comparar o número de casos do estado Paraná com os demais da região sul do Brasil. Trata-se de um estudo transversal descritivo, com as fontes de dados extraídas do Departamento de Informática do Sistema Único de Saúde (DATASUS) por meio do seu Sistema de Informação de Agravos de Notificação (SINAN). A população do estudo são residentes do Estado do Paraná, com faixa etária do 0 até os 69 anos, do período de 2018 a 2019. Além disso, para comparação entre os casos da região sul, utilizou-se as notificações de casos positivos em Santa Catarina e Rio Grande do Sul. Os resultados encontrados foram que no Estado do Paraná, no período referido, obteve 5391 casos confirmados de tuberculose notificados, representando $23,2 \%$ de todos os casos confirmados da região Sul do Brasil. Entre seus residentes a faixa etária mais acometida foi de 20 a 39 anos, representando $45,7 \%$ de todos os casos confirmados, seguido da faixa etária de 40-59 anos $(36,6 \%)$, sendo mais predominante no sexo masculino $(71,3 \%)$. A maior parte dos casos confirmados notificados foi confirmada laboratorialmente $(70,9 \%)$ e a forma mais comum foi a pulmonar (83,3\%). O tipo de entrada mais frequente foi a de casos novos $(84,5 \%)$ e em relação a situação de encerramento a maioria dos casos confirmados evoluiu para cura (55\%), seguido por transferência do paciente $(7,4 \%)$ e por abandono do esquema terapêutico $(5,4 \%)$. Apesar da maioria dos casos evoluírem para cura, a quantidade de casos confirmados 
notificados é expressiva, o que deixa claro, que a tuberculose é, ainda, uma questão de saúde pública no Brasil e no estado. Assim, faz-se necessário um conjunto articulado de ações que consigam fazer uma vigilância epidemiológica adequada, para tal, ações como diagnóstico rápido para novos casos e identificação precoce de resistência bacteriana, bem como tratamentos eficazes e medidas de prevenção, proteção social e suporte aos doentes é de suma importância.

Palavras-chave: Epidemiologia. Mycobacterium tuberculosis. Notificação. Prevenção. Tuberculose. 